\title{
Evidence, Experts and Systematic Reviews. Has COVID-19 changed their importance?
}

\section{Ricardo Maia Ferreira}

Physical Education and Spots Department, N2i, Polytechnic Institute of Maia (Porto). Portugal. rferreira@ipmaia.pt

KEYWORDS: Evidence. Expert. Systematic review.

\section{COVID-19}

In December 2019, in Wuhan's city, a new and fast-speed spread disease was identified ${ }^{1}$. It did not take long for the disease (highly contagious person-to-person) to spread outside the local community, alarming the world scientific circle, including the World Health Organization (WHO). Initially, WHO declared a relatively controlled disease and ranked it as an epidemic, but over the months, with the disease reaching other countries and the number of daily infections rising exponentially worldwide, it did not take long to be considered a pandemic ${ }^{1}$. Different names were given to this pandemic in the media, such as Coronavirus, COVID-19, and SARS-CoV-2, all referring to the same disease. As a pandemic, COVID-19 had different waves and fluctuations in the daily number of new infections, deaths, and hospitalizations ${ }^{2}$. Since the disease is relatively new worldwide, there is still no widespread dissemination of information and scientific studies that specify the correct method to follow in each situation. With these uncertainties, governments had to make decisions following those who could know more about the disease and its behavior, namely experts.

\section{Evidence, Experts, and Systematic reviews}

So far, so good, but there is a small problem: experts' opinions are at the bottom of the scientific evidence pyramid 3 . Thus, although relevant, the scientific community tends to discard such opinions, focusing on other studies with more evidence strength, as systematic reviews (SRs) 4 . However, this pandemic shows that, despite the lack of scientific evidence (experts often had to rely on "raw" data, mathematical models and examples from other countries), their projections, opinions, and suggestions were almost always correct. But how? An expert is someone who has spent years depth studying a topic, is generally recognized by his/her peers as an opinionmaker and has something very important called intuition 5,6 . Often, intuition is dismissed as important by the scientific community; however, in the everyday work environment, it is essential since it allows to make the right decisions, at the right time, often in a fraction of a second 5 . It cannot and should not be confused with luck, since luck does not depend on the judgment. So, intuition is not luck; it is knowledge. But still, how are we letting a group of experts guide us in something so important as a pandemic? 
Should not the scientific community, in particular the information collected through SRs, guide us? The answer is yes and no. The analysis will be made in parts:

- As described earlier, there are different ways to analyze and collect data, in order to understand and study a topic. Under this assumption, different study types may arise. However, their evidence strength varies depending on the study, being SRs what is conventionally defined as the most relevant ${ }^{7}$. SRs are at the top of the scientific evidence pyramid, since this type of study focuses on the collection and analysis of evidence, making in the end, a summary and reflection of the topic studied? .

- As it can be deducted, when a new disease is studied, usually few studies address it. Also, by the importance given worldwide and to have some data to work on, the scientific community pressure for more speed in performing studies, which may result in poor quality studies. These dubious quality studies (which in the past was enough for their refusal) end up being published in scientific journals, as they often look for vogue topics. Consequently, soon, it is expected that the number of COVID-19 SRs is limited, and even those that may arise will have low methodological quality studies included and not explore virusrelated topics in their wholeness, thus affecting their overall quality.

- In addition to the quality of the studies included in the SRs, another factor can also affect their quality: the SR author. Those within the schools' community (universities or polytechnics) know that, usually, at the end of an academic degree (either Bachelor, Master, or Ph.D.), it is required to do at least one scientific study to obtain the respective degree. To justify their choices and make state of the art, students often end up initially performing an SR before performing more experimental studies. A question arises: How relevant can an SR performed by a student be since, being a student, still does not master the investigated topic? Should not the experts be the ones that should have exclusivity to carry out this type of studies, since they master the topic? These questions are difficult to answer. Suppose in one hand, the good about science is that it does not limit who can do studies (regardless of skin color, sex, religion, social background, or academic level), in the other hand, students can have limited critical analysis of the topics they are studying. In that case, their studies often end up being poor in content or even having confusing data that may cause "noise" in the scientific community. It is also true that, because they are students, their work is guided by someone more experienced (preferably with a higher academic degree and/or expert in the field), and when intending to publish in scientific peer review journals, their study is reviewed by different academic personalities, which helps to raise its quality. However, none of these reviewers is the main author of the study. Therefore, it may continue with limitations. Furthermore, by limiting SRs exclusively to experts, despite potentially improving its content and quality, there is a risk of having a biased view on the studied topic. Nevertheless, the scientific community naturally separates the biased/limited/poor quality SRs since high-quality SRs made by experts will tend to have a higher number of citations ${ }^{8}$, reaching a greater impact on the scientific community, compared to SRs made by the students. Yet, although dangerous, biased SRs can also have a high number of citations and help in the development of scientific evidence, since it often leads to the discussion of two (or more) experts with different points of views on the topic studied, creating a prosperous environment for relevant information exchange.

\section{Conclusion}

For the reasons explained earlier, the answer(s) to the question(s) is both yes and no. If in one side, we have to respect the evidence-based practice principles and use the best evidence available 9 (expected to be SRs), on the other side, when the best evidence is not available, and most of the studies are of poor quality, we must descend the evidence pyramid and follow the guidelines of those who know more about the topic, namely the experts. So, what this pandemic is showing is that we should pay more attention and importance to the experts and that this importance should be reflected in the evidence pyramid itself, not only in the hierarchy of their opinions but also open a new level for their SRs (placing them at the top of the pyramid). 


\section{Competing interests}

No financial, legal, or political competing interests with third parties (government, commercial, private foundation, etc.) were disclosed for any aspect of the submitted work (including but not limited to grants, data monitoring board, study design, manuscript preparation, statistical analysis, etc.).

\section{References}

1. World Health Organization. Timeline: WHO's COVID-19 response [Internet]. Available from: https://www.who.int/ emergencies/diseases/novel-coronavirus-2019/interactivetimeline\#!

2. World Health Organization. WHO Coronavirus Disease (COVID-19) [Internet]. Available from: https://covid19.who.int/

3. Murad MH, Asi N, Alsawas M, Alahdab F. New evidence pyramid. Evid Based Med. 2016;21(4):125-7. http://dx.doi. org/10.1136/ebmed-2016-110401
4. Grimshaw J, Freemantle N, Wallace S, Russell I, Hurwitz B, Watt I, et al. Developing and implementing clinical practice guidelines. Qual Health care. 1995;4(1):55-64. http://dx.doi.org/10.1136/ gshc.4.1.55

5. Welsh I, Lyons C. Evidence-based care and the case for intuition and tacit knowledge in clinical assessment and decision making in mental health nursing practice: an empirical contribution to the debate. J Psychiatr Ment Health Nurs. 2001;8(4):299-305. https:// doi.org/10.1046/j.1365-2850.2001.00386.x

6. Rolfe G. Insufficient evidence: the problems of evidencebased nursing. Nurse Educ Today. 1999;19(6):433-42. https://doi. org/10.1054/nedt.1999.0346

7. Harris JD, Quatman CE, Manring MM, Siston RA, Flanigan DC. How to write a systematic review. Am J Sports Med. 2014;42(11):2761-8. https://doi.org/10.1177/0363546513497567

8. Villanueva T, Donato H, Escada P, Sousa C, Reis M, Matos R. Thoughts about the Impact Factor. Acta med Port. 2020;33(10):633-4. https://doi.org/10.20344/amp.14773

9. Sackett DL, Rosenberg WM, Gray JM, Haynes RB, Richardson WS. Evidence based medicine: what it is and what it isn't. BMJ. 1996;312:71. https://doi.org/10.1136/bmj.312.7023.71 